DOI Number: 10.30520/tjsosci.682699

\title{
HAVACILIK KAZASI VE PILLT HATASI KAVRAMI ÜZERİNE BİR DEĞERLENDİRME
}

\author{
AN EVALUATION ON THE PILOT ERROR CONCEPT AND AIRCRAFT ACCIDENT
}

\author{
Meltem AKCA ${ }^{1}$ \\ https://orcid.org/0000-0001-5544-5929
}

\section{$\ddot{\mathbf{O} z}$}

Havacılık sektörü her geçen gün gelişme göstermektedir. Havacılık sektörünün gelişiminde teknolojik yeniliklerin rolü oldukça önemlidir. Havayolu taşımacılık faaliyetlerine yönelik politikalar da sektörün hızlı bir şekilde büyümesi üzerinde tetikleyici olmaktadır. Havacılık sektöründe emniyet unsuru taşımacılık faaliyetlerinin vazgeçilmez bir parçasıdır. Uçuş operasyonlarının gerçekleştirilmesinde görevli kişilerin birincil amacı emniyetin sağlanmasıdır. Bu kapsamda havacılık sektörünün tüm birimlerinde emniyetin taşıdığı değer azımsanamayacak derecede yüksektir. Havacılık sektörü son yirmi yılda güçlü bir ivme yakalamış, yolcu, hava aracı, kargo bazında büyüme eğilimleri göstermiş ve havacılık ile ilgili diğer sektörlerin de gelişimini hızlandırmıştır. Bu süreçte havacılık otoritelerinin düzenlemeleri, hava aracı teknolojilerinin gelişimi gibi faktörler ile hava aracı kazalarında azalma gözlemlenmiştir. Ancak havacılık sektörü büyüme hızı doğrultusunda havacılık kazalarındaki azalma oranlarının daha düşük olduğunu söylemek mümkündür. Havacılık kazalarına ilişkin raporlardan elde edilen veriler doğrultusunda kaza nedenleri araştırılmakta ve çeşitli boyutlarda ele alınmaktadır. Kamuoyu nezdinde dikkat çekici olan nedenlerden biri de pilot hatasıdır. Bu çalışmada havacılık kazası, pilot hatası, kaza nedenleri irdelenmiş ve konu ile ilgili yapılan araştırma sonuçları derlenmiştir. Araştırma sonucunda kaza nedenlerinin aynı anda farklı boyutlar altında ele alınabileceği, pilot hatası ile ilgili demografik değişkenlerin evrensel özellik taşımadığı sonucuna ulaşılmıştır.

Anahtar kelimeler: Havac1lık Kazası, Pilot Hatası, Kaza Nedenleri

JEL Sinıflandırma: R41, R49

\begin{abstract}
The aviation industry is developing day by day. The role of technological innovations in the development of the aviation sector is very important. Policies for air transportation operations are also triggering the rapid growth of the sector. Safety in the aviation industry is an indispensable part of transport activities. The primary purpose of the employees involved in carrying out flight operations is to ensure safety. In this context, the value of safety in all units of the aviation sector is considerably high. The aviation sector has gained strong momentum in the last two decades, demonstrated accretion trend in the base of passenger-aircraft-cargo, and accelerated the development of other aviation-related sectors. In this process, decreases in aircraft accidents have been observed with factors such as regulations of aviation authorities and development of aircraft technologies. However, it is possible to say that the rate of decrease in aviation accidents is lower in line with the growth rate of the aviation sector. In line with the data obtained from aviation accidents reports, causes of accidents are investigated and discussed in various dimensions. One of the reasons that attract attention to the public opinion is the pilot error. In this study, the concepts of aviation accident, pilot error, accident causes are examined and the results of the studies are compiled from descriptive point of view. As a result of the research, it was found that the causes of accidents could be embraced under different dimensions at the same time and demographic variables related to pilot error do not have universal characteristics.
\end{abstract}

Keywords: Aviation Accident, Pilot Error, Causes

JEL Classification: R41,R49

\footnotetext{
${ }^{1}$ Dr. Öğretim Üyesi, Alanya Alaaddin Keykubat Üniversitesi Gazipaşa Havacılık ve Uzay Bilimleri Fakültesi, Havacılık Yönetimi Bölümü, meltem.akca@alanya.edu.tr
} 


Year:4, Volume:4, Number:7 / Yul:4, Cilt:4, Sayt:7 / 2020
$\begin{aligned} & \text { The } \\ & \text { Social } \\ & \text { Science }\end{aligned}$

\section{GİRİŞ}

Havacılık kazaları, pilot hatası gibi kavramlar kamuoyu nezdinde dikkat çekici olmakla birlikte havacılık emniyeti, can ve mal güvenliğinin sağlanması, toplumun havayolu taşımacılığına yönelik talebinin arttırılması ile havayolu işletmelerinin finansal ve operasyonel sürdürülebilirliği üzerinde önem arz etmektedir.

Gelişen teknoloji ile havacılık sektöründeki sistemsel güvenilirliğin artması, insan faktörü ilişkili emniyet kavramının önemli hale gelmesinde etkilidir (Nagel,1988). Teknolojik gelişmeler ile birlikte havacılık sistemlerinin değişimi pilot görevlerini de etkilemektedir. (Baker, Qiang, Rebok ve Li, 2008). Havacılık sektöründeki ilgili teknolojik ve sistemsel yatırımların amaçlarından biri de havacılık kazalarının azaltılması ve pilot hatası sorununun önlenmesidir. Havacılık kazalarına ilişkin araştırma raporlarına göre pilotların durumsal farkındalıklarını kaybetmeleri kaza nedenlerinin başında yer almaktadır. Konu ile ilgili yapılan literatür taramasında havacılık kazalarında pilot hatasının en önemli faktör olduğunu ortaya çıkaran araştırmalara rastlanmıştır (Liu, Chi ve Li, 2013; Sharma ve Malik, 2002; Rashid vd., 2010).

Havacılık kazalarının tek bir faktörün değil birden fazla sistemsel sorunun etkileşimi sonucu gerçekleştiği kabul edilse bile bireysel faktörler bu etkileşim üzerinde belirleyici olabilmektedir (Salmon, Walker ve Standon, 2016). Araştırmacılar, pilot hatasının bireysel ve demografik değişkenlere göre farklılık gösterip göstermediğini çeşitli çalışmalarda incelemiş ancak evrensel nitelikte kabul edilen bir sonuca ulaşamamışlardır. Bu kapsamda bu araştırmada havacılık kazaları ile ilgili yapılan çalışmalar incelenmiş ve bulguları derlenmiştir. Ayrıca, çalışmada havacılık kazaları nedenlerinden bahsedilmiş ve pilot hatası kaynaklı hava aracı kazalarına ilişkin bilimsel çalışmalar üzerinden bir değerlendirme yapılmıştır.

\section{KAVRAMSAL ÇERÇEVE}

\subsection{Havacılık Kazası ve Nedenleri}

Hava aracı ile uçuş operasyonlarının başladığı günden bu yana hava aracı kazaları yaşanmaktadır. Hava aracının motor çalıştırma, taksi yapma, uçuş operasyonu, iniş ve kalkış manevraları esnasında bir ya da daha fazla kişinin yaralanması ya da hava aracinın zarar görmesi ile oluşan olaya hava aracı kazası denir (Gopal, 2000). Devlet Hava Meydanları İşletmesi Havacılık Terimleri Sözlüğü'nde Hava Aracı Kazası: "Uçuş harekâtı esnasında, kişilerin tali nedenlerle ve/veya kendi kendini veya birbirlerini yaralamalart veya uçuş ekibi ve yolcular için ayrilan yerler dişında saklanarak kaçak seyahat edenlerin yaralanmaları hariç olmak üzere, hava aracı içinde veya hava aracından kopan parçalarda dâhil olmak üzere hava aracının herhangi bir parçasının çarpmasiyla veya hava basıncına maruz kalmak suretiyle çok ağır derecede yaralanmasl, motor ve aksesuarlarda meydana gelen arıza ve hafif hasarlar hariç olmak üzere hava aracının fiziksel yapısının veya performansının ve uçuş karakteristiğinin menfi yönde etkilendiği ve bunların değiştirilmesi veya tamirini gerektirecek derecede hasar ve arızalanması, hava aracının kaybolması veya enkaza ulaşılamayacak bir yere düşmesi ile sonuçlanan olaylardır." şeklinde tanımlanmaktadır (DHMİ,2011).

Hava aracı olayı ise, bir hava aracına ilişkin çalışma güvenliğini etkileyen ya da etkileme riski bulunan kaza dışındaki hadisedir. Bununla birlikte, hava aracı ciddi olayı da yüksek kaza olasılığı olma durumunu gösteren, bir şahsın uçuş amacıyla hava aracına binmesinden, hava aracından en son kişinin inmesi anına kadarki süreçte hava aracının işletilmesi, çalışması ile ilişkili olay olarak ifade edilmektedir. Hava aracı kazası ve hava aracı ciddi olayı arasındaki 
fark ise olay ya da kaza sonrası ortaya çıkabilmektedir (Ulaşım Emniyeti İnceleme Merkezi Başkanlığı, 2018).

Havacılık sektörünün teknolojinin gelişimi ile gösterdiği değişim kaza oranlarının azalmasında etkili olmaktadır. 1999 yılından bu yana dünya genelinde ölümcül kaza oranı (1 milyon uçuş içinde) \%95 azalış göstermiş̧tir (Airbus, 2018). Uluslararası Hava Taşımacılığı Birliği (IATA)'ne göre 2018 yılında dünya genelinde 4.3 milyar yolcu taşınmış ve 46.1 milyon uçuş gerçekleşmiştir. IATA, 2018 yılı için havacılık operasyonlarına ilişkin kaza oranının 1.35 (1 milyon uçuş içinde) düzeyinde olduğunu belirtmiştir (IATA, 2019). Ancak, havacılık sektöründeki gelişim ve emniyet performansı artışlarına rağmen havacılık kazalarındaki pilot hatası payının, havacılık kazaları azalış oranından daha düşük bir seyir izlediği gözlemlenmektedir (Salmon, Walker ve Stanton, 2016; Weigmann ve Shappel, 2001).

2019 yılında dünya genelinde havayolu işletmeleri ile ilgili 283 kaza olayı yaşanmış ve 20 havacılık kazası ölümcül kaza olarak kayıtlara geçmiştir. Bu kazaların 3 tanesi kalkış aşamasında, 10 tanesi düz uçuşta, 3 tanesi yaklaşma safhasında 4 tanesi de inişte gerçekleşmiştir (Aviation Safety Network, 2020). Ölümcül olmayan kaza istatistikleri ele alındığında ise veriler değişim göstermektedir. Örneğin IATA emniyet raporlarına göre 2018 yılında 62 hava aracı kazası gerçekleşmiştir (IATA, 2019).

Şekil 1: 2019 Yılı Havacılık Kazalarının Uçuş Safhalarına Göre Dağılımı

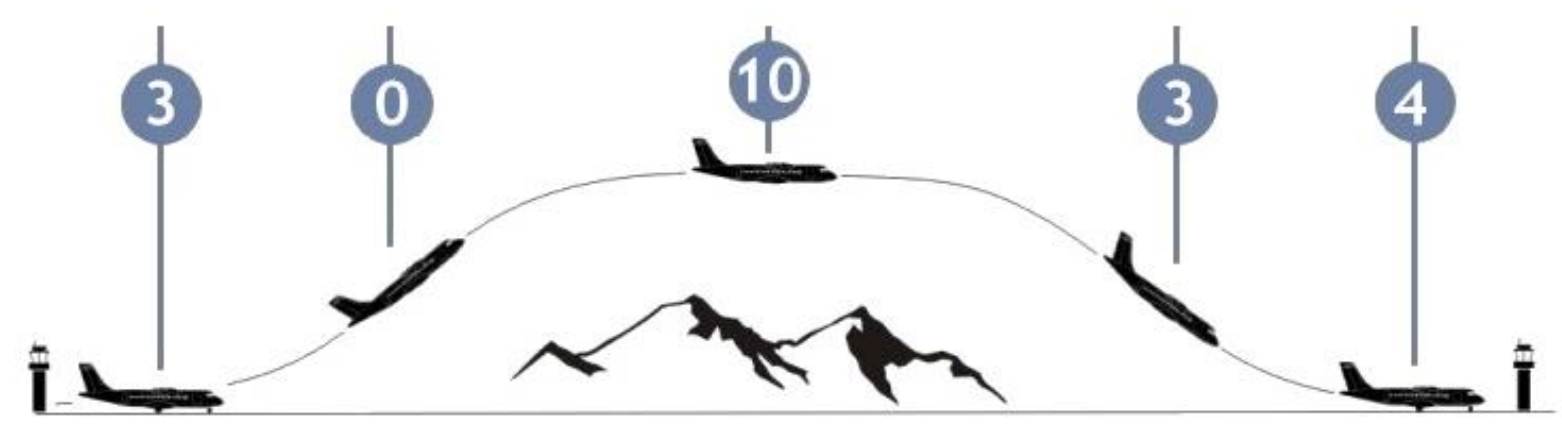

Kaynak: (Airbus, 2018)

Kazalara ilişkin istatistiki bilgiler incelendiğinde, iniş ve yaklaşma aşamalarında daha çok kaza olayı yaşandığını söylemek mümkündür (Airbus, 2018). Bununla birlikte, ticari havayolu işletmelerinin 2017-2018-2019 yıllarındaki ölümcül kazalarına ilişkin bilgiler ise aşağıdaki tabloda yer almaktadır. 
Tablo 1: Ticari Havayolu İşletmeleri Ölümcül Kaza Göstergeleri

\begin{tabular}{|c|c|c|c|}
\hline Göstergeler & 2019 & 2018 & 2017 \\
\hline Havayolu işletmelerinin ölümcül kaza sayıları & 20 & 14 & 10 \\
\hline Havayolu işletmelerinin ölümcül kazalarındaki ölü sayıları & 283 & 555 & 44 \\
\hline \multicolumn{4}{|l|}{ Uçuş Safhası } \\
\hline Düz Uçuş & 10 & 9 & 3 \\
\hline Yaklaşma & 3 & 2 & 3 \\
\hline Tirmanma & 0 & 1 & 2 \\
\hline İniş & 4 & 2 & 2 \\
\hline Kalkış & 3 & 0 & 0 \\
\hline Toplam & 20 & 14 & 10 \\
\hline \multicolumn{4}{|l|}{ İşletme Türü } \\
\hline Kargo & 6 & 3 & 5 \\
\hline Yolcu & 14 & 11 & 5 \\
\hline Toplam & 20 & 14 & 10 \\
\hline \multicolumn{4}{|l|}{ Bölgesel Dağılım } \\
\hline Asya & 2 & 4 & 3 \\
\hline Afrika & 3 & 4 & 2 \\
\hline Güney Amerika & 1 & 1 & 0 \\
\hline Kuzey Amerika & 11 & 1 & 3 \\
\hline Okyanus Bölgesi & 0 & 0 & 0 \\
\hline Merkez Amerika & 0 & 1 & 1 \\
\hline Avustralya & 0 & 1 & 0 \\
\hline Avrupa & 3 & 2 & 1 \\
\hline Toplam & 20 & 14 & 10 \\
\hline
\end{tabular}

Kaynak: (Aviation Safety Network, 2020) 
Türk Hava Sahasında ise 1919 yılından günümüze kadar 53 ölümcül kaza gerçekleşmiş ve bu kazalarda 1032 kişi hayatını kaybetmiştir. Ülkemizde 13 Eylül 1942 ve 26 Ocak 2019 yılları arası gerçekleşen havacılık kaza sayısı (ölümcül olan ve ölümcül olmayan, Türkiye sınırlarında gerçekleşen) ise 133'tür (Aviation Safety Network, 2020). Bununla birlikte, Türkiye sınırları dişında Türkiye menşeli havayolu işletmelerinin ölümcül ve ölümcül olmayan hava aracı kazaları da olmuştur. Ülkemizde hava aracı olayı, hava aracı ciddi olayı ve hava aracı kazalarına ilişkin durumlar Ulaştırma ve Altyapı Bakanlığı bünyesinde Ulaşım Emniyeti İnceleme Merkezi tarafından araştırılmaktadır. Hava aracı olaylarının bildirimi ve incelenmesi ise Sivil Havacılık Genel Müdürlüğü bünyesinde gerçekleştirilmektedir (Ulaştırma ve Altyapı Bakanlığı, Ulaşım Emniyeti İnceleme Merkezi Başkanlığı, 2019).

Hava aracı kazası bir ya da birden fazla faktörün bir araya gelmesi sonucu oluşmaktadır. Kazanın gerçekleşme nedeninin ortaya çıkarılabilmesi havacılık sektörünün emniyeti açısından son derece önemlidir. Havacıllk kazalarına ilişkin faktörler-nedenler farklı isimler altında sınıflandırılsa bile genel olarak bakıldığında benzer nedenlerin belirleyici olduğu bilinmektedir. Bu bakış açısıyla havacılık kazalarına ilişkin nedenler; hava aracı ile ilgili nedenler, hava trafik kontrol ile ilgili nedenler, kargo ile ilgili nedenler, çarpışmalar, harici nedenler, yangın, uçuş ekibi kaynaklı nedenler, iniş-kalkış kaynaklı nedenler, bakım-onarım kaynaklı nedenler, meteorolojik koşullara ilişkin nedenler ve bilinmeyen nedenler olarak gruplandırılmaktadır (Aviation Safety Network, 2020).

Hava aracı sistemleri, ekipmanları, hava aracı parçaları ile ilgili sorun ve hatalardan kaynaklı kazalar hava aracı ile ilgili nedenler arasında yer almaktadır. Pilot ve kontrolör arası iletişimde yaşanan sorunlar, yanlış anlama, uçuş kurallarına ilişkin yanlış bilgilendirme, hatalı talimat verme ya da gerekli bilgilendirmeyi yapmama sonucu oluşan hatalar hava trafik kontrol ve seyrüsefer hizmetleri kaynaklı nedenler arasındadır. Havacılık tarihindeki en önemli kazalar arasında yer alan Tenerife faciasında kontrolör ve pilot arasındaki iletişim sorunu sebebiyle iki hava aracı havalimanında çarpışmış ve yüzlerce kişi yaşamını yitirmiştir (Molesworth ve Estival, 2015; Lin vd., 2012). Hava araçlarına aşırı kargo yükleme yapılması, kargonun yanlış yüklenmesi, ağırlık merkezinin dikkate alınmaması ya da yanlış hesaplanması sonucu oluşan kazalarda ise kargo operasyonlarına yönelik nedenler ön plana çıkmaktadır. Hava araçlarının hava sahasında diğer hava araçları ile ya da mânialar ile ya da kuşlar ile çarpışması veya hava aracının yerde başka bir hava aracı ya da mânia ile çarpışması sonucu oluşan kazalar çarpışma nedenli kazalar olarak değerlendirilmektedir. Harici nedenler ise, yabancı bir cisimden dolayı hava aracının etkilenmesi ve zarar görmesi nedeniyle oluşabilecek kaza nedenleridir. Apronda, hangarda, uçak içerisinde oluşabilecek alev alma, yanma, patlama ile ilgili kazaların nedeni de yangın olarak kabul edilmektedir. Uçak içi sigara içiminden hava aracı ekipmanının alev almasına kadar pek çok neden bu kapsamda ele alınmaktadır (Aviation Safety Network, 2020).

İnişte hızlı ya da yavaş olma sonucu oluşabilecek kazalar, inişi kolaylaştıracak sistemlerin kilitlenmesi, kalkış konfigürasyonunun yanlış olması gibi pek çok unsur ise iniş ve kalkış nedenli kazalara sebep olmaktadır. Hava aracının bakım onarımının hatalı yapılması, yanlış parça takılması gibi pek çok neden de havacılık kazalarına zemin hazırlayabilmektedir. Uçak kaçırma, sabotaj, bombalama, terörist faaliyet, pilotun intihar etmesi gibi nedenler güvenlik ile ilgili nedenlerdir. Ayrıca, buzlanma, sis, tehlikeli bulutlar, volkan patlamaları sonucu oluşan kül bulutları, türbülans, fırtına, yağış, şimşek gibi doğa olayları kaynaklı nedenler meteorolojik nedenler olarak ele alınmaktadır (Winter vd., 2020). Bilinmeyen nedenler, kazanın tanımlanamadığı ya da radardan kaybolan ve bulunamayan uçaklara ilişkin nedenleri ifade etmektedir. Uçuş ekibi nedenleri ise alkol-ilaç-uyuşturucu kullanımı, oryantasyon 
bozukluğu, yorgunluk, uykusuzluk, mental sorunlar, durumsal farkındalıktan yoksunluk, iletişim sorunları olarak kabul edilmektedir (Wilson, 2002; Sexton ve Helmreich, 2000; Connell, Mellone ve Morrison, 2000). Bazı durumlarda ise kazaya neden olan unsur, aynı anda birden fazla başlık altında değerlendirilebilmektedir (Aviation Safety Network, 2020).

Uslu ve Dönmez (2016) çalışmalarında havacılıkta küçük hataların büyük facialara sebebiyet verebileceğini vurgulamış ve insan hatası, teknik arıza, kuş çarpması, meteorolojik koşullar, yıldırım çarpması gibi unsurları kaza nedeni örnekleri olarak sıralamışlardır. Yazarlar, başka bir çalışmalarında havacılık kazalarının büyük kısmının 1950'li yıllarda teknik faktörler, 1970'li yılların ardından insan faktörleri ile ilgili olduğu belirtmiş ve 1990 ve 2000'li yıllardan sonra ise örgütsel faktörlerin önem kazandığının altını çizmişlerdir (Uslu ve Dönmez, 2017). Yavuz, Temiz, Özdemir ve Deniz (2015) ise hava aracı kaza raporlarına yönelik gerçekleştirdikleri incelemelerinde kazaya neden olan faktörlerin meteorolojik koşullar, pilotaj, hava trafik kontrol, yangın ve teknik sistemler ile ilişkili olduğunu saptamışlardır.

\subsection{PILOT HATASI}

Mekanik ve teknolojik sistemlerin gelişmesi ve güvenilirliklerinin artması neticesinde hava aracı kazalarının birçoğunun insan hatası ya da pilot hatası kaynaklı gerçekleştiği ifade edilmektedir (Gopal, 2000). Li, Baker, Grabowski ve Rebok (2001) da havacılık kazalarının $\% 80$ 'inin ve havacılık olaylarının \%50'sinin pilot hatası ile ilişkili olduğunu belirtmektedir.

Havacılık sektöründe hatalar mekanik ve insan hataları olmak üzere ikiye ayrılmaktadır. Teknolojik ve sistemsel hatalar mekanik hatalar kapsamındadır. İnsan hataları ise karar verme hataları ve beceri temelli hatalar olarak ele alınmaktadır (Wiegmann ve Shappell, 2001; Shappel vd., 2017). Amaç gerçekleştirme sürecinde yapılan hatalarda karar vericinin bilinçli olarak tasarladığı planın mevcut durum ya da olay için yetersiz olması ya da uygun olmaması sonucu oluşan hatalar karar verme hatalarıdır. Uçuş operasyonuna yönelik süreçlerin zayıf yönetimi, alternatifler arası uygun olmayan tercihler, bilginin yanlış yorumlanması ya da bilginin yanlış kullanılması ile oluşan hatalar karar verme hatalarına ilişkin örneklerdir. Beceri temelli hatalar ise kişinin farkında olmadan ya da gözden kaçırarak sebep olduğu hatalardır. Kişinin sürekli gerçekleştirdiği rutin davranışlara yönelik hatalar bu grup altında değerlendirilmektedir. Bir cihazı yanlışlıkla açma/kapama, talimatı unutma, kontrol listesindeki bir unsuru fark etmeden atlama gibi dikkatsizlik sonucu oluşabilecek hatalar beceri temelli hataları meydana getirmektedir. Beceri temelli hatalar ile karar verme hataları uçuş operasyonunun emniyetini tehlikeye sokabilecek sonuçlara zemin hazırlayabilmektedir. $\mathrm{Bu}$ nedenle hata yönetim sistemlerinin etkinleştirilmesi, can ve mal güvenliğinin sağlanarak havacılık faaliyetlerinin sürdürülebilirliği üzerinde önem arz etmektedir (Plant ve Stanton, 2012; Wiegmann ve Shappell, 2001; Shappell vd., 2017).

Hava aracı kazalarına ilişkin incelemelerde pilot hatası kaynaklı olaylarda, pilot hatası birinci faktör iken pilotu bu hataya yönlendiren ve arka planda mevcut olan çeşitli operasyonel ve teknik faktörler de yer almaktadır (Sarter ve Alexander, 2000). Havacılık kazaları sonucunda sıklıkla zikredilen bir kavram olan pilot hatasının ayrıntılı bir şekilde ele alınması gerekmektedir. Pilot hatası; hava koşulları, mekanik hata, kontrolör hatası, pilotun ani rahatsızlığg gibi sebeplerden kaynaklanmadan uçuşun uygun bir şekilde seyir etmesi esnasında pilot dikkatsizliği ve pilotun önemsiz şeyler üzerine odaklanması sonucu meydana gelen hata türüdür (Li ve Harris, 2006). Pilot hatası meydana geldiğinde diğer tüm faktörler de kaza olayını hızlandırmaktadır (Gopal, 2000). Pilot hatasını tetikleyen faktörler arasında yorgunluk, zihinsel ve fiziksel iş yükü, korku, kişiler arası iletişimde zayıflık, karar verme 


TJSSS

sorunlarının olduğu belirtilmektedir (Helmreich, 1997; Helmreich, 2000). Hata davranışı; algı, beceri-kontrol ve bilgi analizi gibi çeşitli davranışsal ilkeler temelinde ele alınmaktadır (Roberts, Golder ve Chick, 1980). Bu nedenle pilot hatasını sadece bireysel faktörler ile ilişkilendirmek doğru değildir. Ayrıca pilot hatası altında yatan nedensel faktörleri açıklayabilecek epidemiyolojik veri eksikliği pilot hatası kavramını derinlemesine irdeleyecek çalışma sahasını da kısıtlamaktadır (Li vd., 2001).

Pilotluk, yoğun performans gerektiren bir meslektir. Pilotluk mesleğinin gerektirdiği bilişsel yetkinliklerin yanı sıra iletişim, koordinasyon, denetleme ve karar verme becerilerinin de operasyonların yönetiminde kişiyi yönlendirebilecek nitelikte olması gerekmektedir. $\mathrm{Bu}$ nedenle pilotaj eğitiminde ve pilot adayı istihdamında ayrıntılı sınav süreçleri bulunmaktadır. Özellikle son yıllarda yaşanan kazalarda insan unsuru kaynaklı hataların sıklikla raporlanması, pilot adayı seçim süreçlerinde adayların eğitim başarılarının yanı sıra psikolojik sağlamlılıkları üzerine de odaklanılmasında etkili olmaktadır.

Pilotluk mesleği, karmaşık bilgilerin olduğu çevrede teknolojiyi etkin kullanarak güçlü ekip iletişimi ile operasyonları yönetebilme yetkinliği gerektirir (Helmreich, 2000). Pilotluk mesleğinin tanımlanmasında bilgileri analiz edebilme gücünün önemi psikolojik arka planın da güçlendirilmesi temelinden beslenmektedir (Li vd., 2001). Pilotlar elde ettikleri bilgileri süreçsel olarak analiz ederek uçuş operasyonunu yönetmektedir. Bilgi süreçleme modeline göre, pilotluk mesleğinde üç temel görev unsuru mevcuttur. Bunlar; 1) bilgi toplama, 2) karar verme ve 3) uygulamadır. Bu süreçte bir hata yapılması pilot hatası olarak da kavramlaştırılan sorunu ortaya çıkarmaktadır. Örneğin, pilot hatası kaynaklı uçak kazalarının birçoğunda pilotun karar verme sorunsalı yaşamasına neden olan unsurlardan birinin meteorolojik koşullar olduğu ifade edilmektedir (Li vd., 2001). Pilotun meteorolojik koşullara ilişkin veri elde etme, iletişim, karar verme ve uygulama süreçlerini etkin kullanamamasının kaza oluşumu üzerinde etkili olduğu vurgulanmaktadır.

Pilot hatası ile ilişkilendirilen stres modeli ise stresörlere yönelik reaksiyonun bir adaptasyon süreci olduğu ve üç aşamadan meydana geldiği belirtilmektedir. İkaz reaksiyonu, direnme (metanet) ve tükenme (kopma-boşalım) bu sürecin unsurlarıdır (Green, 1985). Pilotun çeşitli durumlarda stresörlere yönelik vereceği reaksiyon karar verme durumunu göstermektedir. Green'e (1985) göre pilotun başa çıkmak zorunda olduğu ve karşılaştığı stresörler pilota yönelik performans talebini arttırmakta ya da pilotun performanssal yeteneklerini azaltmaktadır. $\mathrm{Bu}$ nedenle pilot hatası oluşumu üzerinde etkili olabilecek faktörlerin belirlenmesi havacılık kazalarının önlenmesi üzerinde önem arz etmektedir.

\section{YÖNTEM VE BULGULAR}

$\mathrm{Bu}$ araştırmada havacılık kazaları ile ilgili makaleler taranmış ve araştırma sonuçları özetlenmiştir. İkincil kaynaklardan elde edilen veriler doğrultusunda genel bir değerlendirme yapılmıştır. Makale başlığında "accident" ve "pilot error" kelimeleri geçen erişime açık 25 eser incelenmiş ancak 10 araştırmanın havacılık kaza raporlarının analiz edilmesi sonucu ortaya çıkarıldığı tespit edilmiştir. Bu kapsamda araştırma sonuçlarına göre elde edilen bulgular Tablo-2'de belirtilmiştir. 
Tablo 2: Havacılık Kazaları ve Pilot Hatası ile İlgili Çalışmalar

\begin{tabular}{|c|c|}
\hline Yazar & Bulgu \\
\hline Li vd., (2001) & $\begin{array}{l}14 \text { yıl süresince meydana gelen kazalar incelenmiş ve kazaların \%38'inin } \\
\text { pilot hatası kaynaklı olduğu saptanmıştır. Yaş ve uçuş süresi deneyimi } \\
\text { arttıkça pilot hatasının azaldığı tespit edilmiştir. Yıllık operasyonel gelir } \\
\text { bakımından büyük havayolu işletmelerinin kaza oranları ve kazalardaki } \\
\text { pilot hatalarının daha küçük işletmelere göre çok daha düşük olduğu } \\
\text { sonucuna ulaşılmıştır. }\end{array}$ \\
\hline McFadden (1997) & $\begin{array}{l}1986 \text { ve } 1992 \text { yılları arasında ABD'de gerçekleşen havacılık kazalarının } \\
\text { \% } 75 \text { 'inin pilot hatası kaynaklı olduğu belirtilmiştir. Geri kalan kısmın, } \\
\text { uçak tasarım sorunları, yetersiz bakım-onarım ve yer personeli kaynaklı } \\
\text { olduğu tespit edilmiştir. }\end{array}$ \\
\hline $\begin{array}{l}\text { Salmon, Walker ve } \\
\text { Standon }(2016)\end{array}$ & $\begin{array}{l}\text { Yazarlar } 2009 \text { yılında } 228 \text { kişinin ölümü ile sonuçlanan kazaya iliş̧kin } \\
\text { inceledikleri kaza raporlarında kazaya sebep olan sistemsel sorunun } \\
\text { kokpit ekibi tarafından anlaşılamaması, duruma ilişkin farkındalığın } \\
\text { kaybedilmesinin hava aracı kontrolünün de kaybolmasına zemin } \\
\text { hazırladığını belirtmişlerdir. Hava aracı sorununun tespit edilememesi, } \\
\text { gerekli olan prosedürün uygulanmasını engellemiştir. Bu kaza örneği ele } \\
\text { alınarak, havacılık kazalarının tek bir sistemsel sorun yerine insani ve } \\
\text { teknik unsurlara ilişkin karar verme ve uygulama etkileşimindeki } \\
\text { hatalardan kaynaklandığı vurgulanmıştır. }\end{array}$ \\
\hline Baker vd (2008) & $\begin{array}{l}1983 \text { ve } 2002 \text { yılları arasında ABD'de gerçekleşen } 558 \text { havacılık } \\
\text { kazasına (ölümcül olmayan kazalar da dahil edilmiştir) ilişkin raporlar } \\
\text { incelenmiştir. } 558 \text { kaza olayının } 265 \text { tanesi }(\% 47) \text { türbülans harici kötü } \\
\text { hava koşulları ile, } 138 \text { tanesi }(\% 25) \text { türbülans ile ve } 117 \text { tanesi }(\% 21) \text { de } \\
\text { mekanik hatalar ile ilişkilidir. Ayrıca } 558 \text { kaza olayının } 180 \text { tanesinde } \\
\text { pilot hatası olduğu raporlanmıştır. Pilot hatası nedenlerinin ise sırasıyla; } \\
\text { dikkatsizlik, karar verme güçlüğ̈ü, hava aracının kötü yönetimi ve ekip } \\
\text { etkileşimi zayıflığı olduğu ortaya çıkarılmıştır. }\end{array}$ \\
\hline Rebok vd (2009) & $\begin{array}{l}\text { Yazarlar, inceledikleri hava taksi kaza raporlarının \% } 70 \text { 'inde pilot } \\
\text { hatasının birincil faktör olduğunu belirtmişlerdir. Ayrıca hava taksi } \\
\text { kazalarında pilot hatası ile pilot yaşı arasında istatistiksel olarak anlamlı } \\
\text { bir fark olmadığ1 sonucuna ulaşılmıştır. }\end{array}$ \\
\hline Li vd (2006) & $\begin{array}{l}\text { Hava aracı kazalarına ilişkin } 558 \text { olay raporu incelenmiş ve kazaların } \\
\text { sirasıyla türbülans, mekanik hatalar, kalkış ve inişte kontrol kaybı ile } \\
\text { ilişkili olduğu sonucuna ulaşılmıştır. İleri yaştaki pilotların türbülans ile } \\
\text { ilişkili kazalarda, genç yaştaki pilotların ise taksi yapma olaylarında } \\
\text { hatalarının olduğu belirtilmiştir. İleri yaştaki pilotlara kıyasla daha genç } \\
\text { pilotların hava trafik kontrolörü ile iletişimde ve çoklu iş talimatlarında } \\
\text { daha hızlı ve aktif bir performans sergilediği sonucuna ulaşılmıştır. }\end{array}$ \\
\hline
\end{tabular}




\section{TJSSI}

Cardosi (2001)

Pist kazalarının pek çoğunun pilot ve kontrolör hatası kaynaklı meydana geldiği belirtilmektedir. Pist ve apron kazalarında ana faktörün kontrolör ve pilot arası iletişim ve koordinasyon eksikliğinden kaynaklandığı ifade edilmektedir. Yazara göre, taraflar arası iletişim zayıflıkları sonucunda kontrolör kaynaklı hatalar; kontrolörün söylemesi gereken talimatı unutması, pilotu pistte bulunan bir araç hakkında uyarmaması ve pistin kapalı olduğunu pilota bildirmemesi şeklindedir. Pilot ve kontrolör arası iletişim eksikliğinin yanı sıra kokpit ekibi koordinasyon zayıflığı ve hava trafik kontrol birimleri koordinasyon zayıflığı araştırma bulguları arasında yer almaktadır.

Vail (1986)

1972 ve 1981 yılları arasında pilot hatası kaynaklı olduğu belirtilen havacılık kazaları incelenmiş ve kadın pilotların hata oranının erkek pilotların hata oranından daha yüksek olduğu sonucuna ulaşılmıştır. Kadın pilotların kazalarının büyük bir kısmının iniş ve taksi yapma aşamasında gerçekleştiği belirtilmiştir. Erkek pilotlar ise kalkış ve uçuş aşamasında daha çok kaza olayına sebep vermiştir. Erkeklerin pilot hatası kazalarının nedenleri incelendiğinde uçuş öncesi hazırlık ve planlamada yaşanan sorunlar, uçuş hızını muhafaza etme ve yakıt yönetimi olduğu saptanmıştır. Erkeklerin kadınlara kıyasla karar vermede kişisel yargılarını ön plana çıkardığı, kadınların ise sorun çözmede yetenek ve becerilerini kullanmaya çalıştıkları ifade edilmiştir. Sonuçta pilot hatası kaynaklı kazalarda kadınların daha genç olduğu, sertifika düzeylerinin daha düşük olduğu, uçuş sürelerinin de az olduğu tespit edilerek oranların kadınların aleyhinde yorumlanmaması gerektiğinin altı çizilmiştir.

\begin{tabular}{|l|l|}
\hline $\begin{array}{l}\text { Shappell ve } \\
\text { Wiegmann (2004) }\end{array}$ & $\begin{array}{l}\text { Yazarlar 16.000 kazayı incelemiş ve kazaya sebep olan birincil tip } \\
\text { hatanın beceri temelli hatalar, karar verme hataları ve algısal hatalar ile } \\
\text { ilişkili olduğunu saptamışlardır. }\end{array}$ \\
\hline Veillette (2001) & $\begin{array}{l}1987 \text { ve 2000 yılları arasında yaşanan helikopter kazaları incelenmiş ve } \\
\text { kazaların \%76'sının insan hatası kaynaklı olduğu ortaya çıarılmışır. } \\
\text { Uçuş planlama hataları, bilgi değerleme sorunları ve karar vermede } \\
\text { zayıflık hata oluşumunu tetikleyen faktörler olarak değerlendirilmiştir. }\end{array}$ \\
\hline
\end{tabular}

\section{SONUÇ}

Havacılık sektöründe ölümcül kaza oranı 2008 yılında bir milyon uçuşta (tarifeli-ticari) 4.8 iken bu rakam 2018 yılı sonunda 2.59'a düşmüştür (Airbus, 2018). Havayolu işletmelerinin insan faktörü kaynaklı hataları azaltmak için otomasyona yönelmesi ve yatırımlarını bu yönde kullanması kaza oranlarının azalmasında etkili olmuştur (ICAO, 2019; Connell, Mellone ve Morrison, 2000). Ayrıca, çarpışma ikaz sistemi, yere yakınlık ikaz sistemi, kokpit kaynakları yönetim sistemi gibi pilotu bilgilendiren sistemlerin geliştirilmesi ve daha yoğun kullanılması ile pilot hatası kaynaklı kazalar azalma eğilimine girmiştir. Bu kapsamda, kokpit sistemleri (navigasyon, otopilot, elektronik cihazlar, trafik ve meteorolojik uyarı ikaz sistemleri) geliştirilme amaçlarının; pilot farkındalığını arttırmak, iş yükünü hafifletmek ve pilot hatasını en aza indirgemek olduğunu söylemek mümkündür (Casner,2009). Bununla birlikte, kaza oranlarının azalmasında devlet politikaları ve havacılık otoritelerinin yaptırımlarının önemi de 
azımsanamayacak derecede yüksektir. Literatür taramasında havacılık kazaları ile ilgili yapılan araştırma sonuçlarına göre pilot hatası kaynaklı kazalarda pilotların demografik özellikleri ve kaza olayı arasındaki ilişkilerin araştırılmaya çalışıldığ gözlemlenmiştir. Araştırma sonuçları farklılık göstermekle birlikte her kazanın kendine özgü nedenleri olabilmektedir.

Araştırmacı için havacılık kazaları ve pilot hatası ile ilgili yapılan literatür taramasının ilgi çeken sonuçlarından biri de cinsiyet değişkeni üzerine olmuştur. Kadınların eğitiminin artması istihdam olanaklarını genişletmektedir. Büyüyen ve gelişen havacılık sektöründe istihdam edilen kadın sayısı giderek artış göstermektedir. Havacılık sektörünün maskülen olarak görülmesi nedeniyle kadınların pilotluk mesleğine olan ilgisi daha geç başlamıştır. Mesleğin sosyal statüsü, prestiji, ekonomik imkânları kadınları bu sektöre yönelik cezbetmiştir. Dünya genelinde kadın pilotların sayısı toplam pilot sayısının yaklaşık \%5'i kadardır (Women in Aviation, 2019; Vail, 1986; Vail ve Ekman, 1986). Bu nedenle kadınların sektörde pilot olarak istihdam olma tarihinin çok eskiye dayanmaması kadın pilotların yaş ortalamasının, erkek pilotların yaş ortalamasından düşük olmasına sebep olmaktadır. Ayrıca genel olarak bakıldığında, kadın pilotların toplam uçuş saati sürelerinin de erkek pilotlardan az olduğu belirtilmektedir (Francesco ve Hakel,1981; Mcfadden, 1997). Mc Koonce (2002) çalışmasında gerekli eğitimlerin verilmesinin ardından kadın ve erkek pilot performansı arasında fark olmadığını ancak kadın pilotların tecrübe-deneyim süresinin biraz daha uzun olduğunu ifade etmektedir. Havacılık sektöründe kadınların istihdam edilmesi ve uçuş sürelerinin arttırılması ile deneyim kazanmalarının sağlanması için insan kaynakları uygulamaları geliştirilmeli ve kadın pilot adayları desteklenmelidir. Kadın pilotlar ile pilot adaylarına ilişkin rol model çalışmalarının, eğitim ve mentorluk faaliyetlerin kadınların kariyer gelişimi üzerinde etkili olması muhtemeldir. McFadden (1997) kadın pilotların pilot hatası kaynaklı kaza istatistiklerinin bazı raporlarda yüksek olmasının tek başına cinsiyet değişkeni ile açıklanmasının doğru olmadığını, sonuçların gruplar arası farklılıklardan kaynaklanan sayısal değerleri de göz önüne alarak yorumlanması gerektiğini vurgulamıştır. Stojiljkovic ve arkadaşları (2018) ise havacılık kazalarının araştırılmasında sadece fiziksel koşulların ve pilotun demografik özelliklerinin incelenmesinin doğru olmadığını belirtmiş ve pilot hatası kavramının tüm yordayıcı faktörleri ile dikkate alınması ve daha kapsamlı şekilde incelenmesi gerekliliğini vurgulamışlardır. Li, Baker, Grabowski ve Rebok (2001) da çevresel, araçsal ve meteorolojik koşulların pilot hatası olarak adlandırılan faktör üzerinde belirleyici olduğunu ifade etmişler ve kavramın sadece pilotların kişisel özellikleri ile ilişkilendirilmemesi gerektiğinin önemi üzerinde durmuşlardır. Livingstone (2008) ise havacılık kazalarının pilot hatasının ötesinde insan hatası olarak ele alınması ve pilot ile uçuş operasyonunun yürütülmesinde ve kontrol edilmesinde görevli tüm birimleri kapsaması gerektiğini belirtmiştir.

Günümüzdeki teknolojik gelişmelere rağmen kaza raporlama sistemlerinin pilot hatasına ilişkin kavramsal arka planının yetersiz olduğu ifade edilmektedir (Wiegmann ve Shappell, 2001). Bu nedenle veri tabanları ile ilişkili analizlerde kaza önleyici uyarıcılar tatmin edici düzeyde değildir. Ayrıca veri tabanlarında pilot hatası olarak tanımlama yapmak yerine kazaya neden olan pilot hatasının öncülleri ile birlikte daha detaylı ve kapsamlı bir şekilde sisteme işlenmesinin ilişkisel analizlerin gücünü arttıracak bir yaklaşım olacağ öngörülmektedir (Ecer ve Ay, 2009).

Son olarak, Stojiljkovic ve arkadaşları (2018) kokpit ergonomisi üzerinde durulması ve ergonomik unsurların iyileştirilmesinin pilot hatasını azaltacak bir yaklaşım olacağını savunmuşlardır. Özdoğan ve arkadaşları (2005) ise yaptıkları araştırmalarında havalimanı 


TJSS|

yakını kazalarda hayatta kalma oranının daha fazla olduğu sonucuna ulaşmış ve havalimanı çevresinde acil durumlara müdahale edebilecek tıbbi birimlerin mevcudiyetinin havacılık kazalarında hayatta kalma olasılığını arttıracak bir önlem olacağını belirtmişlerdir.

Bu çalışmada havacılık kazalarında pilot hatası ile ilgili verileri paylaşan makaleler taranmış ve ikincil verilerden yararlanılmıştır. İleriki araştırmalarda nitel araştırma yöntemlerini daha kapsamlı bir şekilde ele alan çalışmaların yürütülmesinin sonuçların bilimselliğini arttıracağı öngörülmektedir. Ayrıca birincil verilerden yararlanmak, araştırma yöntem bilimini güçlendirmek ve istatistiksel olarak daha tatmin edici bulgulara erişmek için pilotların katılımı ile mülakatlar yapılmalıdır.

\section{KAYNAKÇA}

Airbus (2018) A Statistical Analysis of Commercial Aviation Accidents 1958-2018, Airbus, file://UStatistical-Analysis-of-Comercial-Aviation-Accidents-1958-2018, Erişim Tarihi: 27.12.2019

Aviation Safety Network(2020). Accident Database, ASN, https://aviation-safety.net/database, Erişim Tarihi: 05.01.2020.

Baker, S. P., Qiang, Y., Rebok, G. W. \& Li, G. (2008). Pilot error in air carrier mishaps: longitudinal trends among 558 reports, 1983-2002. Aviation, space, and environmental medicine, 79(1), 2-6.

Bishop, J.(2018, 12 Eylül). You'll Never Guess Which Country Has The Most Female Pilots, Forbes, https://www.forbes.com/sites/bishopjordan, Erişim Tarihi: 12.11.2019

Cardosi, K., \& Center, V. (2001). Controller and pilot error in surface operations. In 4th USA/Europe Air Traffic Management R\&D Seminar, 5-9.

Casner, S. M. (2009). Perceived vs. measured effects of advanced cockpit systems on pilot workload and error: Are pilots' beliefs misaligned with reality?. Applied Ergonomics, 40(3), 448-456.

Causse, M., Dehais, F., Péran, P., Sabatini, U., \& Pastor, J. (2013). The effects of emotion on pilot decision-making: A neuroergonomic approach to aviation safety. Transportation research part C: emerging technologies, 33, 272-281.

Connell, L.J., Mellone, V.J.\&Morrison, R. (2000). Cabin Crew Safety Information and The NASA Aviation Safety Reporting System, NASA.

DHMİ (2011) Havacılık Terimleri Sözlüğü, DHMİ, Ankara.

Dismukes, R. K., \& Nowinski, J. (2007). Prospective memory, concurrent task management, and pilot error. Attention: From theory to practice, 225-236.

Ecer, S. Ve Ay, G.(2009). Hava Taşıtı Kazalarını Önlemede Yeni Gelişmeler. Bilgi Ekonomisi ve Yönetimi Dergisi, 4(1), 85-94.

Ergai, A., Cohen, T., Sharp, J., Wiegmann, D., Gramopadhye, A., \& Shappell, S. (2016). Assessment of the human factors analysis and classification system (HFACS): Intrarater and inter-rater reliability. Safety science, 82, 393-398.

Francesco, A.M. and M.D. Hakel (J981), Gender and Sex as Determinants of Hireability of Applicants for Gender-Type Jobs, Psychology of Women Quarterly, 5, 747-746.

Gatta, A. (2018). Rethınkıng Human Error In Aviatıon Accidents: Regulatory And Standard 


Year:4, Volume:4, Number:7 / Yul:4, Cilt:4, Sayl:7 / 2020
$\begin{aligned} & \text { The } \\ & \text { Social } \\ & \text { Science }\end{aligned}$

Practices In The Nigerian Aviation Industry. Internatıonal Journal Of Arts, Languages And Business Studies, 1(1).187-202.

Gopal, P. (2000). Analysis of factors leading to pilot error accidents in civil aviation. Ind $J$ Aerospace Med, 44(1), 34-38.

Green RG. (1985). Stress and accidents. Aviat Space Environ Med, 56:638-41.

Helmreich, R. L. (1997). Managing human error in aviation. Scientific American, 276(5), 6267.

Helmreich, R. L. (2000). On error management: lessons from aviation. Bmj, 320(7237), 781785.

IATA.(2019). Safety Report 2018, Edition 55, IATA Press, Montreal.

ICAO.(2019). State of Global Aviation Safety 2019, ICAO Publications.

Koonce, J. M. (2002). Human factors in the training of pilots. CRC Press.

Li, G., Baker, S. P., Grabowski, J. G., \& Rebok, G. W. (2001). Factors associated with pilot error in aviation crashes. Aviation, space, and environmental medicine, 72(1), 52-58.

Li, G., Grabowski, J. G., Baker, S. P., \& Rebok, G. W. (2006). Pilot error in air carrier accidents: Does age matter?. Aviation, space, and environmental medicine, 77(7), 737741.

Li, W. C., \& Harris, D. (2006). Pilot error and its relationship with higher organizational levels: HFACS analysis of 523 accidents. Aviation, Space, and Environmental Medicine, 77(10), 1056-1061.

Lin, C. J., Lin, P. H., Chen, H. J., Hsieh, M. C., Yu, H. C., Wang, E. M. Y., \& Ho, H. L. (2012). Effects of controller-pilot communication medium, flight phase and the role in the cockpit on pilots' workload and situation awareness. Safety science, 50(9), 17221731.

Liu, S. Y., Chi, C. F., \& Li, W. C. (2013, July). The application of human factors analysis and classification system (HFACS) to investigate human errors in helicopter accidents. In International Conference on Engineering Psychology and Cognitive Ergonomics. Springer, Berlin, Heidelberg.

Livingstone, J.(2008) Gains from Losses: System Safety Commentary on Accidents and other Events There is More to "Human Error" Than Just Pilot Error. Journal of System Safety, 44(6), 1-2.

McFadden, K. L. (1996). Comparing pilot-error accident rates of male and female airline pilots. Omega, 24(4), 443-450.

McFadden, K. L. (1997). Predicting pilot-error incidents of US airline pilots using logistic regression. Applied ergonomics, 28(3), 209-212.

Molesworth, B. R., \& Estival, D. (2015). Miscommunication in general aviation: The influence of external factors on communication errors. Safety science, 73, 73-79.

Nagel, D. C. (1988). Human error in aviation operations. In Human factors in aviation. Academic Press.

Özdoğan, M., Tosun, N., Ağalar, F., Eryılmaz, M., \& Aydınuraz, K. (2005). An evaluation of civilian aviation accidents in Turkey from 1955 to 2004. Ulus Travma Acil Cerrahi 


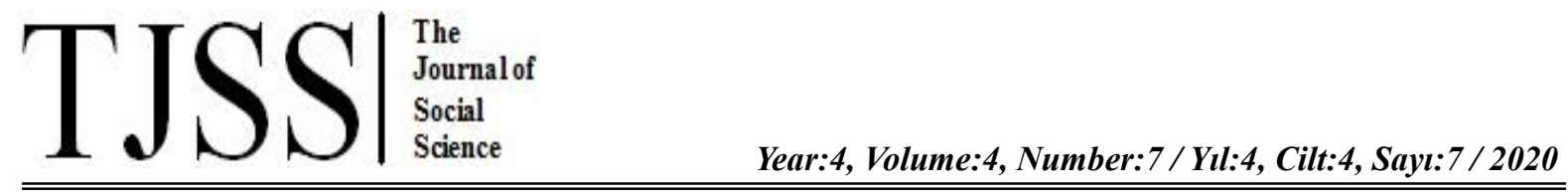

Derg, 11(4), 318-323.

Plant, K. L., \& Stanton, N. A. (2012). Why did the pilots shut down the wrong engine? Explaining errors in context using Schema Theory and the Perceptual Cycle Model. Safety science, 50(2), 300-315.

Rashid, A., Cottenier, T., Greenwood, P., Chitchyan, R., Meunier, R., Coelho, R., ... \& Joosen, W. (2010). Aspect-oriented software development in practice: tales from AOSD-Europe. Computer, 43(2), 19-26.

Rebok, G. W., Qiang, Y., Baker, S. P., \& Li, G. (2009). Pilot age and error in air taxi crashes. Aviation, space, and environmental medicine, 80(7), 647-651.

Roberts, J. M., Golder, T. V., \& Chick, G. E. (1980). Judgment, oversight, and skill: A cultural analysis of P-3 pilot error. Human Organization, 39(1), 5-21.

Salmon, P. M., Walker, G. H., \& Stanton, N. A. (2016). Pilot error versus sociotechnical systems failure: a distributed situation awareness analysis of Air France 447. Theoretical Issues in Ergonomics Science, 17(1), 64-79.

Sanders, M. G., Hofmann, M. A., \& Neese, T. A. (1976). Cross-validation study of the personality aspects of involvement in pilot-error accidents. Aviation, space, and environmental medicine, $1-8$.

Sarter, N. B., \& Alexander, H. M. (2000). Error types and related error detection mechanisms in the aviation domain: An analysis of aviation safety reporting system incident reports. The international journal of aviation psychology, 10(2), 189-206.

Sexton, J. B., \& Helmreich, R. L. (2000). Analyzing cockpit communications: the links between language, performance, error, and workload. Human Performance in Extreme Environments, 5(1), 63-68.

Shappell, S., Detwiler, C., Holcomb, K., Hackworth, C., Boquet, A., \& Wiegmann, D. A. (2007). Classifying and Understanding Human Error-Human Error and Commercial Aviation Accidents: An Analysis Using the Human Factors Analysis and Classification System. Human Factors-Journal of the Human Factors and Ergonomics Society, 49(2), 227-242.

Shappell, S., Detwiler, C., Holcomb, K., Hackworth, C., Boquet, A., \& Wiegmann, D. A. (2017). Human error and commercial aviation accidents: an analysis using the human factors analysis and classification system. In Human Error in Aviation.Routledge.

Shappell, S. A., \& Wiegmann, D. A. (2004, November). HFACS analysis of military and civilian aviation accidents: A North American comparison. In Proceedings of the Annual Meeting of the International Society of Air Safety Investigators. Australia: Gold Coast.

Sharma, W. C. A., \& Malik, G. C. H. (2002). Human factors in helicopter and transport aircraft accidents in IAF. Indian Journal of Aerospace Medicine, 46(1), 7-14.

Stojiljkovic, E., Bijelic, B., Grozdanovic, M., Radovanovic, M., \& Djokic, I. (2018). Pilot error in process of helicopter starting. Aircraft Engineering and Aerospace Technology, 90(1), 158-165.

UHUM(t.y.) İstatistiklerle Hava Taşımacılığı Kazaları, Mühendis ve Makina, 48(566).3-19.

Ulaştırma ve Altyapı Bakanlığı Ulaşım Emniyeti İnceleme Merkezi Başkanlığı. (2019). 2018 
Yılı Faaliyet Raporu, Ankara.

Uslu, S. ve Dönmez, K. (2017). Hava Trafik Kontrol Kaynaklı Uçak Kazalarının İncelenmesi, Mehmet Akif Ersoy Üniversitesi Sosyal Bilimler Enstitüsü Dergisi, 9(18), 271-287.

Uslu, S., Dönmez, K. (2016). Geçmişten Günümüze Havacılık Kazalarının Sebeplerindeki Değişimler Üzerine Bir İnceleme, Sobider, 3(9), 222-239.

Vail, G. J. (1986). The Social Psychological Aspects of Pilot-Error Accidents: Male vs. Female. International Society of Air Safety Investigators, 29-32.

Vail, G. J., \& Ekman, L. G. (1986). Pilot-error accidents: Male vs female. Applied Ergonomics, 17(4), 297-303.

Veillette, P. R. (2001). Human error cited as major cause of US commercial EMS helicopter accidents. Flight Safety Digest, 20(4-5), 1-39.

Wiegmann, D. A., \& Shappell, S. A. (2001). A human error analysis of commercial aviation accidents using the human factors analysis and classification system. HFACS, 1-17.

Wilson, G. F. (2002). An analysis of mental workload in pilots during flight using multiple psychophysiological measures. The International Journal of Aviation Psychology, 12(1), 3-18.

Winter, S. R., Rice, S., Capps, J., Trombley, J., Milner, M. N., Anania, E. C., ... \& Baugh, B. S. (2020). An analysis of a pilot's adherence to their personal weather minimums. Safety Science, 123, 1-7.

Women in Aviation (2019) Soar To New Heights With A Career In Aviation And Aerospace A Statistical Analysis of Commercial, Wai https://www.wai.org/education/resources/aviationcareers-brochure Erişim Tarihi: 20.11.2019

Yavuz, V., Temiz, C., Özdemir, E. T., \& Deniz, A. (2015). Avrupa Bölgesi için Kaza-Kırım Raporlarının İncelenmesi. Avrupa Bilim ve Teknoloji Dergisi, 2(5).155-160. 